University of Wollongong

Research Online

Faculty of Business - Papers (Archive)

Faculty of Business and Law

$1-1-2017$

Big data and disaster management: a systematic review and agenda for future research

Shahriar Akter

University of Wollongong, sakter@uow.edu.au

Samuel Fosso Wamba

Toulouse Business School, samuel.fosso.wamba@neoma-bs.fr

Follow this and additional works at: https://ro.uow.edu.au/buspapers

Part of the Business Commons

Research Online is the open access institutional repository for the University of Wollongong. For further information contact the UOW Library: research-pubs@uow.edu.au 


\title{
Big data and disaster management: a systematic review and agenda for future research
}

\author{
Abstract \\ The era of big data and analytics is opening up new possibilities for disaster management (DM). Due to \\ its ability to visualize, analyze and predict disasters, big data is changing the humanitarian operations and \\ crisis management dramatically. Yet, the relevant literature is diverse and fragmented, which calls for its \\ review in order to ascertain its development. A number of publications have dealt with the subject of big \\ data and its applications for minimizing disasters. Based on a systematic literature review, this study \\ examines big data in DM to present main contributions, gaps, challenges and future research agenda. The \\ study presents the findings in terms of yearly distribution, main journals, and most cited papers. The \\ findings also show a classification of publications, an analysis of the trends and the impact of published \\ research in the DM context. Overall the study contributes to a better understanding of the importance of \\ big data in disaster management.

\section{Disciplines \\ Business}

\section{Publication Details} \\ Akter, S. \& Fosso Wamba, S. (2019). Big data and disaster management: a systematic review and agenda \\ for future research. Annals of Operations Research,283 939-959.
}




\title{
BIG DATA AND DISASTER MANAGEMENT: A SYSTEMATIC REVIEW AND AGENDA FOR FUTURE RESEARCH
}

\begin{abstract}
The era of big data and analytics is opening up new possibilities for disaster management (DM). Due to its ability to visualize, analyze and predict disasters, big data is changing the humanitarian operations and crisis management dramatically. Yet, the relevant literature is diverse and fragmented, which calls for its review in order to ascertain its development. A number of publications have dealt with the subject of big data and its applications for minimizing disasters. Based on a systematic literature review, this study examines big data in DM to present main contributions, gaps, challenges and future research agenda. The study presents the findings in terms of yearly distribution, main journals, and most cited papers. The findings also show a classification of publications, an analysis of the trends and the impact of published research in the DM context. Overall, the study contributes to better understand the importance of big data in disaster management.
\end{abstract}




\section{Introduction}

Numerous natural disasters strike across the globe every year, killing thousands, displacing many more, and destroying billion-dollars of property and infrastructure (Altay and Green, 2006; Galindo and Batta, 2013). For example, the economic impacts of the 2010 and 2011 Queensland floods were estimated to about A\$ 6.8bn in direct losses (Menhart, 2015), and the 2016 Japan's Kyushu Island earthquake economic losses were estimated to be between US \$25 billion and US\$ 30 billion. The overall global total economic losses from these disasters were estimated to about US\$ 175 billion in 2016 (Swiss Re Institute Sigma, 2017). The impacts of disaster events can disrupt the progress and developmental efforts of nations, often pushing them many years back (Smith and Matthews, 2015; Huang and Cervone, 2016). Moreover, McGuire (2012) noted that a major cause of these natural disasters is the changing climate, which affects human lives while exceeding the economic toll. As the number of disasters has increased over the years, a concern has grown worldwide about how to extend crtical knowledge and innovation to prevent, mitigate and manage disaster operations (Tin et al., 2013). In support of this argument, Zheng et al. (2013, p. 451) stated that "the techniques to efficiently discover, collect, organize, search, and disseminate real-time disaster information have become national priorities for efficient crisis management and disaster recovery tasks". Although it may not be possible to entirely prevent all disasters, it is well acknowledged that an effective use of innovative technology can, to a great extent, reduce the magnitude of loss in life and property (Adriana et al., 2014; Starr and Wassenhove, 2014). Indeed, emerging technological innovations including social media, location-based systems, radio frequency identification, and big data analytics (BDA) are considered as powerful tools that may help all stakeholders during the disaster management cycle.

BDA, defined a "holistic process to manage, process and analyze 5 Vs (i.e., volume, variety, velocity, veracity and value) in order to create actionable insights for sustained competitive advantages" (Fosso Wamba et al., 2015), is now considered as a powerful tool that can transform all industries including manufacturing (Wilkins, 2013), retailing (Marr, 2015a), healthcare (Marr, 2015b) and emergency services (Fosso Wamba et al., 2015). In this regard, Mehrotra et al. (2013) suggested that BDA can assist in creating the next generation of emergency response technologies as it has the potential to mitigate the effects of disasters by enabling access to critical real-time information. Combined with real-time analytics, such 
information can definitely help to prevent and face disasters. It can indeed prevent any damage to life and property by detecting various disasters, such as earthquakes, wild fires, cloudbursts, tornadoes and volcanic activities (Wang et al., 2016).

The role of big data in disaster management (DM) has been evolving. Nowadays, scientists are facing one of the biggest challenges of managing large volumes of data generated at times of disasters. As a huge amount of disaster-related data is getting generated, traditional data storage and processing systems are facing challenges in fulfilling performance, scalability and availability needs of big data (Grolinger et al., 2016). Moreover, the current data storage systems are diverse and offer very limited scope for collaboration. Therefore, there is a need to develop techniques that can help efficiently in data integration, aggregation and visualization, while optimizing the decision-making process, since the quality of decisions taken by the DM officials depends on the quality of available information (Emmanouil and Nikolaos, 2015). Mehrotra et al. (2013, p. 6) emphasized that "accurate and timely assessment of the situation can empower decision makers during a crisis to make more informed decisions, take appropriate actions, and better manage the response process and associated risks". Thus, it is essential to reconsider how data on disasters should be properly and efficiently produced, organized, stored, and analyzed (Hazen et al., 2014).

Prior research activities have extensively discussed the use of timely, accurate and effective disaster information in disaster management and preparation scenarios (Hsritidis et al., 2010, Zhang et al., 2012, Velev and Zlateva, 2012). The most common data resources include news/articles/blogs from web, social networks platforms such as Twitter, Facebook, and Flickr, as well as multimedia data like images and videos (Tin et al., 2013). By utilizing BDA in the disaster context, Wang et al. (2016) conducted a systematic study on emergency communication networks, drawing on the fact that BDA provides all possible solutions to understand any disaster-related issues while the results from analysis may assist in optimally deploying the limited resources. In addition, Hristidis et al. (2010) conducted a comprehensive survey of the efforts on utilizing and advancing the management and on data analysis to serve disaster management situations. The extant literature suggests the need to collect, manage, find, and present disaster information in the context of DM phases: preparation, response, recovery, and 
mitigation (Bish et al., 2014; Jahre et al., 2007; Pyakurel and Dhamala, 2017; Wang et al., 2016). Recently, Goswami et al. (2016) reviewed the application of data mining and analytical techniques for predicting, detecting, and developing appropriate DM strategy based on disastergenerated data.

Unlike other reviews on the subject, our review specifically aims to analyze and organize the recent DM literature in the broadest sense, without focusing on the evolution of DM from the beginning up to now, but rather on the latest developments in the DM field. In particular, we have chosen to concentrate on DM studies published in recent years, that is, from 2010 to January 2017; for the corresponding period, we have identified 76 DM-related papers. We have carefully selected our sources using a structured approach to identify the journals with higher value to the academic community as a whole. On the other hand, we have adopted a methodology that visibly differs from the one used in other reviews. The bibliometric and network analysis review methodology is recognized by various authors as an important methodology to be adopted when it comes to carrying out an in-depth analysis of the current state of a field and exploring the related future research directions (e.g., Bouchard et al., 2015; Fahimnia et al., 2015). We categorize the studies according to their status (in terms of publication distribution), research context, authors, and affiliations.

This paper is structured as follows: the next section describes the methodological approach used to conduct the review. This is followed by an analysis of the data collected, and then by a discussion of the results obtained and an outline of suggestions for future research on DM. The final section reports the conclusions.

\section{Methodology}

Application of Big data in DM is yet to fully mature into a specific area of academic research. Through the bibliometric and network analysis, this paper aims to ascertain the current development in the field and acknowledge that there is sufficient scope for a comprehensive study to explore new possibilities and directions for research in the future. 
Gamal (2010) pointed out that academicians and practitioners often make use of journals to obtain and publish the highest level of research outcomes. Therefore, following the systematic review guidelines of Altay and Green (2006), Galindo and Batta (2013) and Akter and Wamba (2016), we focused on studies published in journals with findings that add to the available theoretical body of knowledge and applications. Since we found very few articles published prior to 2010 , we restricted ourselves to consider only relevant papers published between 2010 and January 2017. This resulted in a comprehensive set of articles on the chosen topic. However, it is very likely that we have missed a few papers unintentionally. For our literature review, we have used a four-stage protocol:

1. A search was conducted in the title and abstract field of the SCOPUS database with the following search terms and their variants: (“disaster management" OR "emergency service" OR OR "disaster relief operations" OR "disaster resilience" OR "emergency management") AND "big data". This resulted in a total of 382 relevant articles.

2. The shortlisted articles were then screened to include only the journal articles. This led to a reduced number of 123 articles.

3. From among them, 94 articles were retained after removing the duplicate results using the Mendeley desktop software.

4. Full text articles were retrieved and reviewed individually by all the authors for additional screening. The remaining records were abstracted for analysis. This search brought the final total to 76 articles, spread across 66 journals.

Figure 1 shows the distribution of 76 shortlisted articles by publication year. Through our literature search, we found that there were no specific papers on the topic till 2012, but the growth has improved significantly since then. Interestingly, a dramatic rise in publications can be observed after 2014. This may be due to the fact that big data and its emerging technologies seem to have overtaken every segment of the market and society (Generro et al., 2016). The proven success of big data has motivated practitioners and academicians to identify its role in DM. Hence, researchers have tacitly accepted it as a powerful technique for dealing with disasters, and it is among the most promising research trends of the decade. 


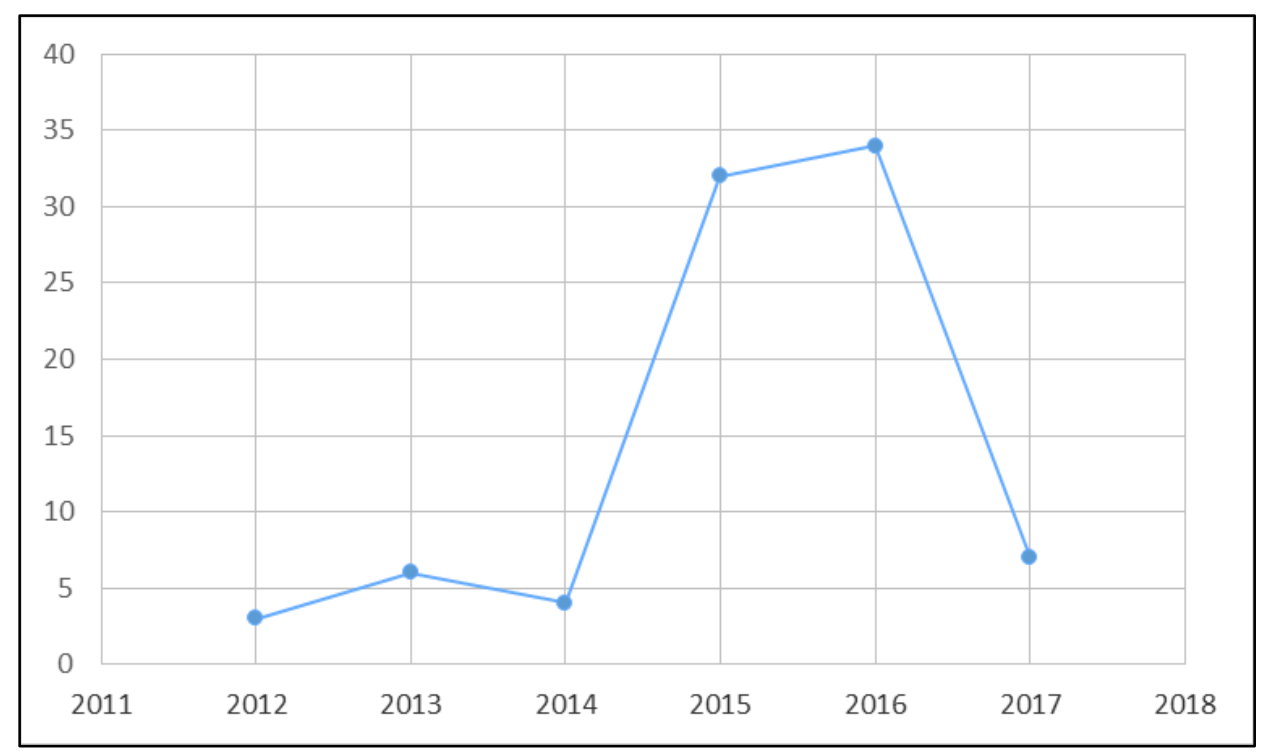

Figure 1: Distribution of shortlisted articles by publication year

\section{Review results and classifications}

In this section, we employ different methods to classify the shortlisted articles based on authors, universities, countries, research methodology, research area, and disaster phase.

\section{(a) Classification by authors}

The shortlisted articles are summarized by authors to identify the researchers with the greatest impact. More than 150 authors have contributed to the body of knowledge through 76 papers published in 66 journals. Significant contributors include Carley, K.M., Kowalchuck, M., Landwehr, P.M., Ye, X and Abdul Samad, S. Figure 2 shows the top five researchers (out of a total of 159), based on their publications. 


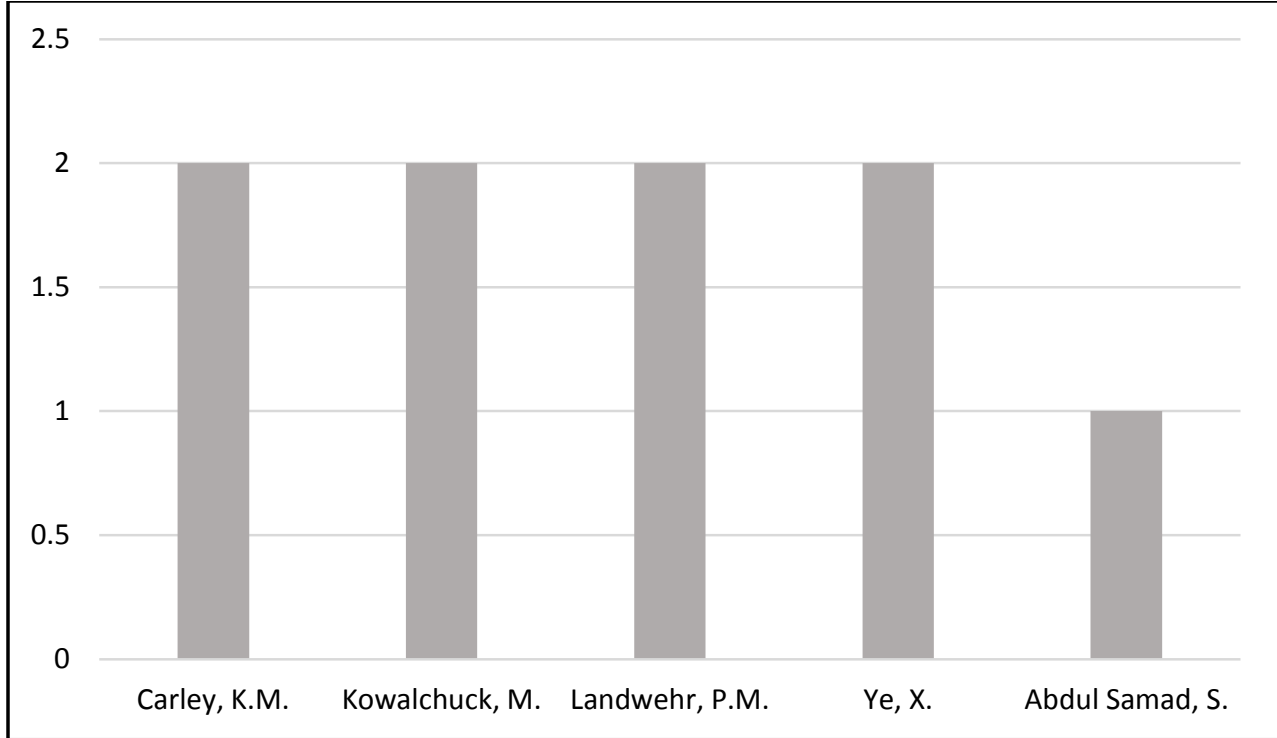

Figure 2: Distribution of shortlisted articles by authors

\section{(b) Classification by universities}

Through our literature review, we realized that a total of 143 universities and institutes have contributed to the area of big data in DM. Such outstanding number may be attributed to the fact that minimizing disasters and their impact have become the pressing need of the hour. Figure 3 shows the top ten universities contributing to this area of research. The majority of articles have been published by the authors from the Wuhan University (3), followed by those from the Collaborative Innovative Center of Geospatial Technology (2), the National Disaster Management Research Institute (2), the Pennsylvania State University (2) and the Arizona State University (2). 


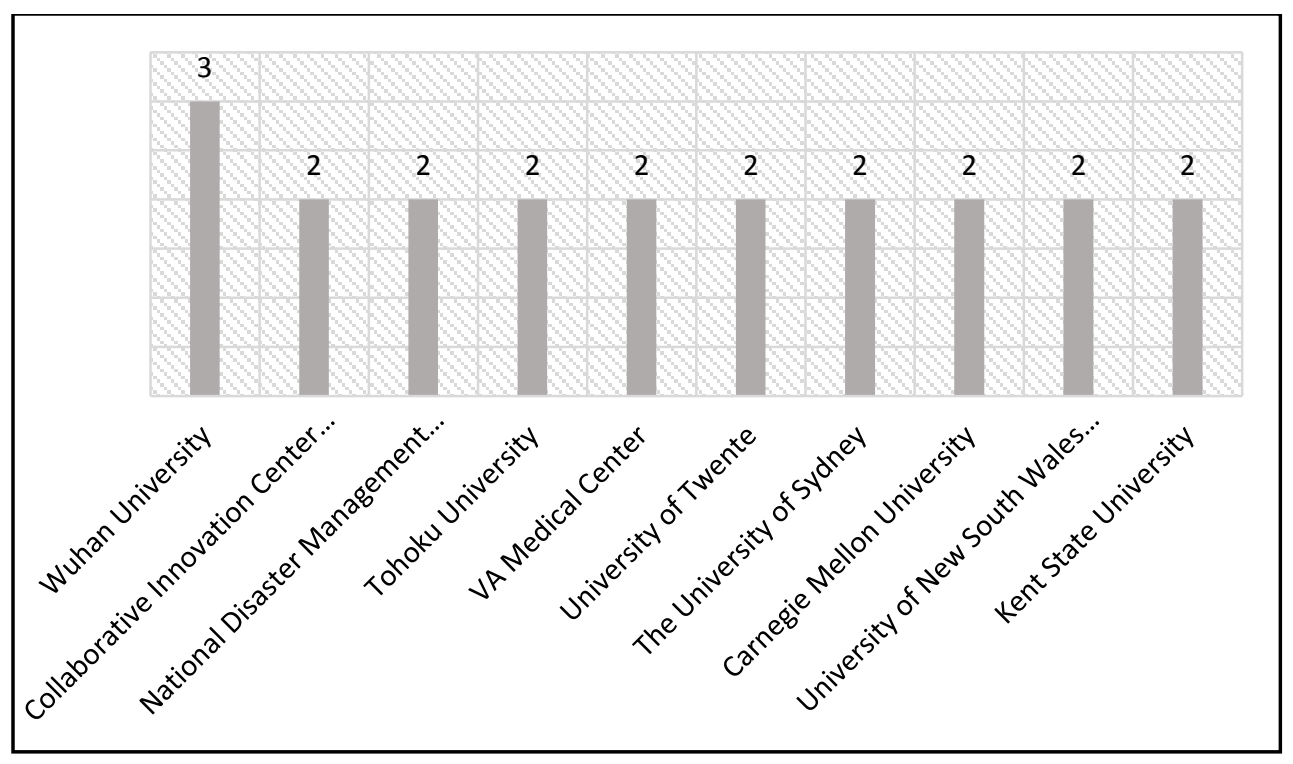

Figure 3: Distribution of shortlisted articles by top universities

\section{(c) Classification by countries}

Our literature review reveals that the contributors are from 30 different countries. Contributions from the United States of America constitute $80 \%$ of the publications. Other significant contributors include China, Australia, Japan, the United Kingdom and France. In fact, this observation is consistent with the previous analysis based on universities as most of them are located in China, South Korea, and the United States of America. Figure 4 presents the top ten

contributors in this area of research.

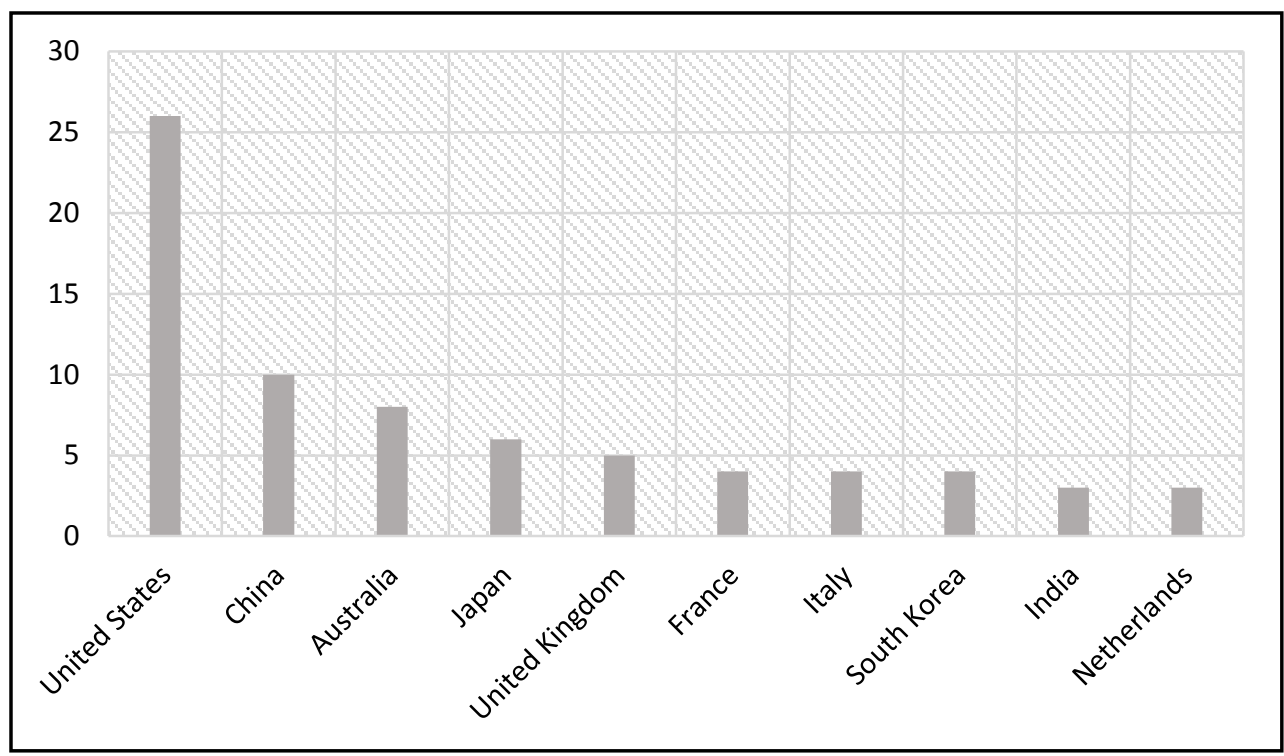

Figure 4: Distribution of shortlisted articles by top countries 


\section{(d) Classification by subject areas}

According to the method chosen for the review, the papers were scrutinized to bring out the major subject areas. In this regard, each paper was examined critically in order to identify the areas where research was performed (see Figure 5). The results indicate that the application of big data in the disaster context has expanded into a broad spectrum of subject areas, including engineering, computer science, social science, medicine, environmental science, etc. It can be seen that out of 76 articles, 24 came from engineering, 23 studies dealt with computer science and social science, 14 studies with medicine and 12 with environmental issues. From the analysis being made, we have observed that more work are still needed in the areas of mathematics, decision sciences and pharmacology.

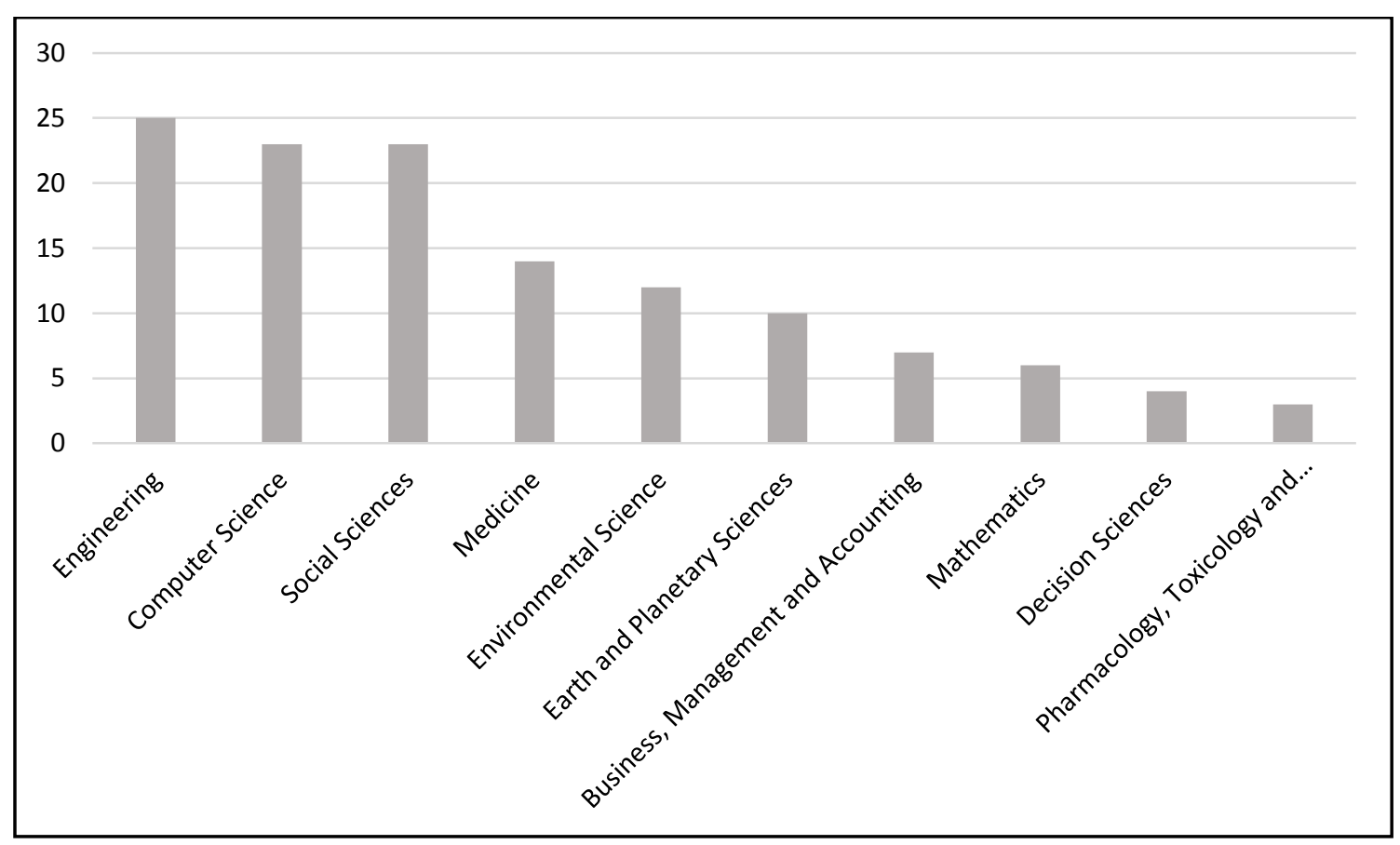

Figure 5: Distribution of shortlisted articles by subject areas

\section{(e) Classification by research methodology}

The distribution of reviewed studies with respect to the research methodologies are shown in Figure 6. It clearly appears that the majority of articles being reviewed use analytical models. These studies focus on how to solve problems in relation to post-earthquake emergency response (Ghosh and Gosavi, 2017), early warning system for biodiversity (Rovero and Ahumada, 2017), welfare impacts of urban disasters (Grinberger and Felsenstein, 2016), etc. This includes the use of semi-Markov model, cloud-based architecture, agent-based models, and P2P cloud network services (Chung and Park, 2016). We also note that an equivalent number of review and 
conceptual studies have been done on DM. On the other hand, we found only a few case studies. This can be explained by the fact that case study research is not well utilized in operations management research (Hassini et al., 2012). Moreover, big data applications in DM area is a relatively new research field, and researchers need to carry out more case studies as it would help in understanding the real issues and problems, something that the case study methodology is well suited for (Rowley, 2002).

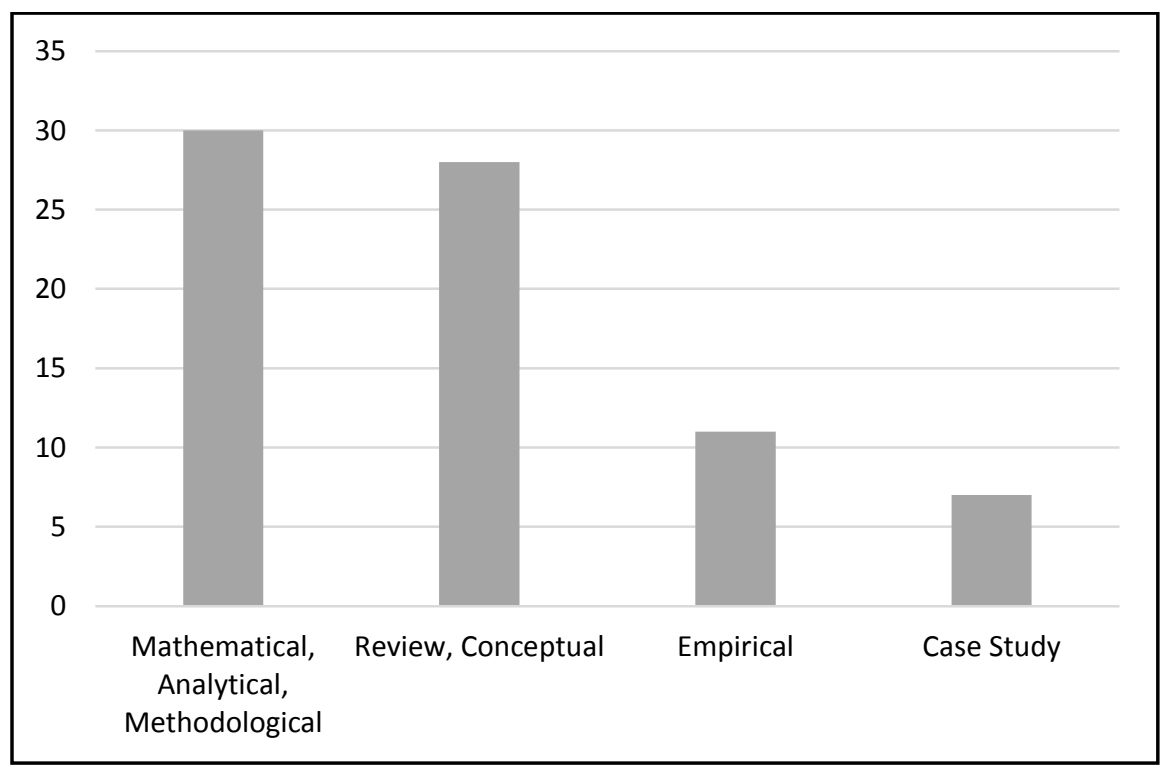

Figure 6: Distribution of shortlisted articles by research methodologies

\section{(f) Classification by disaster phases}

In the literature, the emergency response efforts have been classified into two stages: pre-event and post-event response (Tufekci and Wallace 1998; Altay and Green, 2006). The first stage includes tasks related to prediction and analyses of potential risk and preparedness for mitigation. As for the second stage, it starts while the disaster is still in progress. During this stage, it is very challenging to allocate, coordinate and manage resources.

In the context of DM, the United States emergency management identified four different phases: mitigation, preparedness, response, and recovery (Green, 2002; Waugh, 2000; Altay and Green, 2006), commonly known as DM lifecycle stages. During the mitigation phase, the chances of the disaster happening are prevented and its impacts once it occurs re minimized. The preparedness phase prepares the community or users to react and respond at the time of disaster. This phase 
involves allocation of resources and emergency procedures in order to safeguard life, property, environment, and the socio-economic and political structure of the community. In the recovery phase, actions are taken with a long-term goal to stabilize the community and restore normalcy after the immediate impact of the disaster.

We have categorized the shortlisted articles based on the four phases of DM lifecycle (see Table 1). It can be seen that about $36.8 \%$ of all the articles address the mitigation issue. In these articles, various mitigation strategies and tools, such as power grid disaster prevention and dispatch system (Wang et al., 2016), hybrid decision support system (Drosio and Stanek, 2016), global flood detection system and global flood awareness system, have been proposed to deal with disasters. We note that the response phase follows mitigation in a context of research productivity, with $28.9 \%$ of articles published in this area. However, there are relatively fewer articles $(22.5 \%)$ focussing on the preparedness phase of DM lifecycle. But the phase that clearly needs much attention is disaster recovery, as we obtained only 2 articles $(2.6 \%)$ in this category. Moreover, we note that 2 articles (2.6\%) focussed on general disaster management without specifying any particular phase of disaster while 5 articles $(6.6 \%)$ targeted all the four phases of disaster.

Table 1: Distribution of articles based on the disaster phase

\begin{tabular}{|l|l|}
\hline Disaster phase & Publications \\
\hline Mitigation & Wang et al., 2016; Cinnamon et al., 2016; Chang and Lo, 2016; Harvard et \\
al., 2015; Zeydan et al., 2016; Wang et al., 2016; Drosio and Stanek, 2016; \\
Ang and Seng, 2016; Jian Ping et al., 2016; Koshimura, 2016; Zhao et al., \\
2016; Janke et al., 2016; Moreira et al., 2015; Shakir et al., 2014; Huang and \\
Li, 2015; Wang et al., 2015; Cooper et al., 2015; Albuquerque et al., 2015; \\
Revilla-Ramero et al., 2015; Venkatesan et al., 2015; Lee et al., 2015; \\
Villena-Roman et al., 2014; Araz et al., 2014; Krasuski and Wasilewski, \\
2013; Miranda et al., 2013; Joyce, 2012; Granell and Ostermann, 2016; \\
Cherichi and Faiz, 2016
\end{tabular}




\begin{tabular}{|l|l|}
\hline & $\begin{array}{l}\text { al., 2016; Keon et al., 2015; Johal, 2015; Ram et al., 2015; Haworth and } \\
\text { Bruce, 2015; Li et al., 2015; Radianti et al., 2015; Schultz, 2012; Prewitt, } \\
\text { 2013; Fosso-Wamba et al., 2015 }\end{array}$ \\
\hline Response & $\begin{array}{l}\text { Ghosh and Gosavi, 2017; Hultquist and Cervone, 2017; Papadopoulos et al., } \\
\text { 2017; Erdelj et al., 2017; Palmieri et al., 2016; Tan et al., 2016; Grabowski et } \\
\text { al., 2016; Collins et al., 2016; Vinoth Krishnan et al., 2016; Alamdar et al., } \\
\text { 2016; Haug et al., 2016; Choi, 2016; Chen et al., 2015; Lee et al., 2015; Li et } \\
\text { al., 2015; Bostenaru Dan and Armas, 2015; Miura et al., 2015; Hara and } \\
\text { Kuwahara, 2015; Tomaszewski et al., 2015; Scott and Batchelor, 2013; Bruns } \\
\text { and Liang, 2012; Winquist et al., 2014 }\end{array}$ \\
\hline $\begin{array}{l}\text { Recovery } \\
\text { phase }\end{array}$ & $\begin{array}{l}\text { Grinberger and Felsenstein, 2016; Chung and Park, 2016 } \\
\text { phases }\end{array}$ \\
\hline $\begin{array}{l}\text { Cutts et al., 2015; Murayama and Burton, 2015 } \\
\text { 2015; Huang et al., 2015 }\end{array}$
\end{tabular}

\section{(g) Classification by data clustering}

To identify the major research clusters of this field, the Louvain algorithm was applied to 235 node network using Gephi. We observed that the value of modularity index was 0.15 , which indicates a strong bond among the nodes of any particular cluster. In other words, the papers which are cited together share the same area of interest. Table 1 shows the top publications of each cluster based on PageRank. Based on a careful examination of contents and research areas of the leading papers, the authors of this study identified four research clusters that could be valuable domains for conducting big data research in the disaster context.

The literature classification presented in Table 2 exhibits that researchers in cluster 1 were mainly concerned about the role played by social media platforms, such as Twitter, in times of distress. As people turn to these sites to broadcast their needs and gather timely-relevant information, new software platforms are being deployed to analyze the incoming data from social media. These tweets are also investigated to detect possible seismic events, to compare and contrast the behavior of people during emergency and in relation to national security, and 
extract information using information extraction (IE) techniques. Although social media is a potential source of information for crisis management, information from other sources must also be taken into account. Recent disasters, such as the Southern California Wildfire of 2007 and the Sichuan Earthquake of 2008, have shown that information provided by eye-witnesses through social networking outlets (e.g., Twitter, Instagram, Flickr, and others) can greatly improve situational awareness. Therefore, our cluster 2 studied the potential of Volunteered Geographic Information (VGI), that is, the spatial information collected by volunteers from the public and shared over the Internet. For instance, Kent and Capello (2013) compared the spatial distribution of wildfire and non-wildfire specific user generated content to confirm the presence of a social networking user base that contributed to situational awareness. Poser and Dransch (2010) discussed the opportunities and challenges faced when using VGI for disaster management, specifically focussing on the response and recovery phases.

Realizing the fact that location is an important factor in disaster messages (Gelernter and Mushegian, 2011; Qian et al., 2013), cluster 3 moved ahead with the technique of spatial data mining that refers to the discovery of interesting relationships and characteristics existing implicitly in spatial databases. The researchers in this cluster mainly focussed on proposing effective and efficient clustering techniques for spatial data mining ( $\mathrm{Ng}$ and $\mathrm{Han}, 1994)$, but also a novel join-less approach for efficient co-location pattern mining (Yoo et al., 2006). In addition, researchers in this cluster explored the behaviour of Twitter users under an emergency situation (Mendoza et al., 2010; Mandel et al., 2012) and developed systems that capture the information received from Twitter that helps in avoiding and monitoring emergency situations, like earthquakes (Robinson et al., 2013). The works in cluster 4 contributed to the applications of data mining techniques, electronic commerce, and RFID. For instance, Ngai et al. (2009) applied data mining tools to study customer relationship management, as extracting and identifying useful information and knowledge from customer databases leads to customer value maximization and to the acquisition and retention of potential customers. Ngai and Gunasekaran (2007) and Ngai and Wat (2002) reviewed the literature on electronic and mobile commerce, and provided useful insights into these topics. In addition, RFID has been used to improve garment manufacturing processes (Ngai et al., 2012) and healthcare industries (Ngai et al., 2009). 
Table 2: Distribution of shortlisted articles based on clustering

\begin{tabular}{|c|c|c|c|}
\hline $\begin{array}{c}\text { Cluster } 1 \\
\text { (social media's roles) }\end{array}$ & $\begin{array}{c}\text { Cluster } 2 \\
\text { (Volunteered } \\
\text { geographic } \\
\text { information) }\end{array}$ & $\begin{array}{c}\text { Cluster } 3 \\
\text { (Spatial data mining) }\end{array}$ & $\begin{array}{c}\text { Cluster } 4 \\
\text { (Applications of data } \\
\text { mining) }\end{array}$ \\
\hline Vieweg et al., 2010 & Shelton et al., 2014 & Mendoza et al., 2010 & Boyd and Crawford, 2012 \\
\hline Earle et al., 2010 & $\begin{array}{l}\text { De Albuquerque et al., } \\
2015\end{array}$ & Mandel et al., 2012 & Reddi et al., 2011 \\
\hline Hughes and Palen, 2009 & Craglia et al., 2012 & Robinson et al., 2013 & Ponserre et al., 2012 \\
\hline Zook et al., 2010 & $\begin{array}{l}\text { De Longueville et al., } \\
2010\end{array}$ & $\begin{array}{l}\text { Gelernter and Mushegian, } \\
2011\end{array}$ & Ngai et al., 2012 \\
\hline Kitchin, 2014 & Bengtsson et al., 2011 & Yoo and Shekhar, 2006 & Ngai et al., 2009 \\
\hline $\begin{array}{l}\text { Landwehr and Carley, } \\
2014\end{array}$ & $\begin{array}{l}\text { Poser and Dransch, } \\
2010\end{array}$ & Ozyer et al., 2007 & Oracle (2012) \\
\hline Starbird and Palen, 2010 & $\begin{array}{l}\text { Crawford and Finn, } \\
2015\end{array}$ & $\mathrm{Ng}$ and Han, 1994 & Ngai et al., 2009 \\
\hline Schnebele et al., 2014 & Kent et al., 2013 & $\begin{array}{l}\text { Penurkar and Deshpande, } \\
2014\end{array}$ & Ngai et al., 2008 \\
\hline Vieweg, 2010 & Liang et al., 2013 & Qian et al., 2013 & Ngai and Wat, 2002 \\
\hline Gao et al., H, 2011 & Crooks et al., 2013 & Mukherjee et al., 2015 & $\begin{array}{l}\text { Ngai and Gunasekaran, } \\
2007\end{array}$ \\
\hline
\end{tabular}




\section{Discussion and research agenda}

While the use of big data helps in predicting disasters and preparing safety measures, there are a few challenges that need to be addressed before reaping the benefits from it. The extant literature argues that decision-makers need to address various challenges, such as crisis analytics platform, data governance, data quality, analytics capabilities and evidence-based findings. From our analysis, we found that there are only a few studies that are based on theories. By "theory" we mean "connections among phenomena, a story about why acts, events, structure and thoughts occur" (Sutton and Staw, 1995, p. 378). Therefore, more theory-based research is required to identify the applications of big data in DM. In the following sections, we shed light on various challenges and opportunities of big data research in DM with theoretical insights.

The development of big data-driven crisis analytics platform has many applications that can enhance disaster response. Often, disaster has cascading effects (e.g., Tsunami followed by earthquake) which requires that a real-time analytics platform be developed to prioritize urgent issues, prevent follow-up hazards, coordinate aid organizations and arrange first responders. Thus, it is critical to ensure a crisis analytics platform that is highly disaster-tolerant, reliable, available and secured. The extant literature has largely focused on descriptive (i.e., what happened) or diagnostic analytics (i.e., why did it happen), the big data-driven crisis analytics platform has opened up the opportunity to apply predictive analytics (what will happen).

Emergency services grapple with the massive amount of data arriving through multiple channels, such as first responders, sensors, satellite networks or social media. Therefore, the biggest challenge is to develop a data integration protocol that ensures proper data gathering, modelling and notification systems (Agarwal and Dhar, 2014; Miller, 2013). Emergency services are empowered more than ever before to develop a preemptive disaster management system based on big data. For example, mobile phones, satellites and social media have an enormous amount of location-specific data, the challenge is to know how emergency service and disaster relief 
agencies can usher in big data to provide real-time services using the right channel. In addition, it is also important to develop an emergency communication system and informational hub using text, images, speech, video, maps, crowdsourced data, and formal reports. During a crisis situation, it can help people locate emergency accommodation, food and water, evacuation route, or missing people.

Data quality is the key for developing pre-emptive disaster management in big data environment (Kiron et al., 2014). Poor quality data makes it difficult to assess and use for emergency services (Beath et al., 2012). The potential of big data can be capitalized by addressing the risks of inaccurate and redundant data. Decision-making based on such data might jeopardize the whole rescue operations because mass unfiltered data might threaten privacy (e.g., names and addresses, social security numbers). Overall, the current state of big data remains informal and poorly structured; therefore, it needs to be addressed adequately to ensure data quality.

Big data analytics capability (BDAC) in disaster management refers to the competence to provide solid crisis insights using data management, infrastructure (technology) and talent (personnel) capability to take real-time decisions (Kiron et al., 2014). It remains a critical challenge for emergency and disaster relief agencies to manage all these capabilities equally to leverage big data. Using an entanglement view of sociomaterialism, we argue that the BDAC dimensions do not act in isolation; rather, they act together. They are also constitutively entangled (Orlikowski, 2007) and mutually supportive (Barton and Court, 2012). In this case, Akter et al. (2016)) found support for 11 subdimensions (i.e., BDA planning, investment, coordination, control, connectivity, compatibility, modularity, technical knowledge, technology management knowledge, business knowledge, and relational knowledge) under three primary dimensions (i.e., management capability, infrastructure capability and talent capability). These factors can be taken into account when developing a BDAC model emergency service system. 
Table 3: Future research questions relating to big data in disaster management

\begin{tabular}{|c|c|c|}
\hline $\begin{array}{l}\text { Disaster management } \\
\text { research streams }\end{array}$ & Relevant theories & Future research questions for big data in disaster management \\
\hline Crisis analytics platform & $\begin{array}{l}\text { Big data analytics theories } \\
\text { (Akter et al., 2016; } \\
\text { Davenport et al., 2012; } \\
\text { Davenport, 2013a, b; } \\
\text { Schläfke et al., 2013) }\end{array}$ & $\begin{array}{l}\text { - How can organizations provide real-time analytics, multimodal informatics, } \\
\text { disaster tolerance and context awareness? } \\
\text { - How to develop predictive models rather than descriptive or diagnostic } \\
\text { ones? } \\
\text { - How to provide context aware personalized crisis information using AI, } \\
\text { machine learning, GPS with smartphones? }\end{array}$ \\
\hline Strategic management & $\begin{array}{l}\text { Organizational } \\
\text { ambidexterity (O'Reilly } \\
\text { and Tushman, 2008) and } \\
\text { resource based view } \\
\text { (Barney, 1991) }\end{array}$ & $\begin{array}{l}\text { - How to develop a holistic analytics culture across various functional } \\
\text { divisions to leverage big data? } \\
\text { - How to establish a fit among big data analytics capabilities, strategic } \\
\text { alignment, agility and firm performance? }\end{array}$ \\
\hline Information Systems & $\begin{array}{l}\text { IT capability theories } \\
\text { (Kim et al., 2012) }\end{array}$ & $\begin{array}{l}\text { - What factors influence reliability, visualization, governance, security, and } \\
\text { privacy in using big data for emergency service operations? } \\
\text { - How can an emergency agency use omni-channels to establish big data } \\
\text { analytics protocol? } \\
\text { - What are the big data capability dimensions for emergency and disaster } \\
\text { relief agencies? } \\
\text { - How can a firm leverage big data sources and cloud-based architecture to }\end{array}$ \\
\hline
\end{tabular}




\begin{tabular}{|c|c|c|}
\hline & & produce solid insight on accommodation, food and water? \\
\hline Organizational agility & $\begin{array}{l}\text { Dynamic capability theory } \\
\text { (Teece et al., 2016) }\end{array}$ & $\begin{array}{l}\text { - How to develop dynamic analytics capabilities in disaster management to } \\
\text { address risk and deep uncertainty? } \\
\text { - How can organization develop a robust HR policy to retain and nurture data } \\
\text { scientists in disaster management? } \\
\text { - What types of resource allocations are needed to improve the technical, } \\
\text { statistical and managerial capabilities to deal with big data? } \\
\text { - How can managers in emergency organizations build agility to sense, seize } \\
\text { and transform? }\end{array}$ \\
\hline $\begin{array}{l}\text { Big data system in } \\
\text { private or public cloud }\end{array}$ & $\begin{array}{l}\text { Cloud computing theories } \\
\text { (Chang, 2015) }\end{array}$ & $\begin{array}{l}\text { - How to protect ownership and privacy of data in private cloud? } \\
\text { - Is there any contingency plan for big data in private or public cloud to } \\
\text { minimize risks in the contexts of disasters? } \\
\text { - Is private cloud approach better than public cloud in the context of data loss } \\
\text { by blackout, earthquake, fire, flood, hacking or by other causes. }\end{array}$ \\
\hline Productivity and value & $\begin{array}{l}\text { Value and productivity } \\
\text { (Akter et al., 2016; Ji-fan } \\
\text { Ren et al., 2016) }\end{array}$ & $\begin{array}{l}\text { - To what extent transactional costs can be reduced using big data analytics in } \\
\text { disaster management? } \\
\text { - How to leverage strategic and transformative business values from big data } \\
\text { analytics to develop preemptive disaster management policies? }\end{array}$ \\
\hline
\end{tabular}


When big data integrates with cloud computing, it can tackle various real time challenges to provide critical recovery services in disasters. However, there are some challenges in implementing big data in private or public cloud which includes protecting ownership of data, privacy, security and data loss. Thus, first, it is important to establish data ownership to protect unauthorized sharing. Second, regulatory compliance frameworks should be established and relevant laws (regional, national or international) are required to be met. Finally, to better manage big data, both private and public clouds should come up with contingency or back up plans in the context of data loss by hazards, such as, hacking, fire, flood, and earthquake or power failure (Chang, 2015).

It is important to articulate a solid and compelling emergency service operation case using big data in disaster management. Both in academia and in practice, the extant literature reports a fascinating case that illuminates an emergency service context and applies the methodology, such as defining the problem, reviewing the literature, developing the model by selecting the variables, collecting and analyzing the data and making time critical emergency service and disaster relief decisions. It is known that case study-based research is scarce in the operations management literature. Similarly, as shown in Figure 6, we found only 7 case studies that address the issue of disasters. As we stressed in our results, we believe it is important that case studies be more strongly emphasized. Overall, there are lots of avenues to present non-trivial research questions in this stream and we offer some examples in Table 4 using management theories. According to Starr and Wassenhove (2014,p.934), "Big data analysis brings new insights. It is much easier today to predict some disasters as well as their impact by using greatly improved forecasting methods, for example, in the case of hurricanes.... Big data analysis based on social media traffic will have deep impacts on our knowledge and understanding of behavior in disaster situations".

\section{Limitations and conclusions}

In this study we conducted a review of the literature on the role of big data in resolving disasterrelated problems. We identified 76 papers published between 2010 and January 2017 that were relevant to our review. This review enabled us to identify the trend and to determine the research gaps in the literature. In conclusion, we report the strengths and limitations related to our review 
technique. About the strengths, we adopted a clear and rigorous approach; each author performed the data collection independently and then discussed it with co-authors, thus obtaining an accurate database. We also included all the articles, in order to capture different aspects and behaviors of DM research. Moreover, we believe that the search of papers in title, abstract and keywords fields rather than just searching in key words is a asset, because it avoids the risk of discarding significant papers. Regarding the limitations, we considered only papers that satisfied some specific criteria and with subjects we considered coherent and inherent with DM. For instance, we did not include unpublished works, book chapters and conference proceedings. These decisions could lead to the exclusion of relevant studies and to the limitation of creativity and innovations. This review deployed the SCOPUS database. While aiming for a comprehensive coverage by following rigorous, systematic review and synthesis procedures, the database selection and filtering processes may have omitted some relevant research works. We noted that the majority of articles focused on the mitigation and response phase, and a good number on the preparedness phase, while only two articles targeted disaster recovery. More research is thus needed on how communities should recover from the aftermath of disaster.

\section{Acknowledgement:}

The authors appreciate and gratefully acknowledge constructive comments and literature review support of Deepa Mishra (Indian Institute of Technology, Kanpur, India ), which improved the quality of our study.

\section{References}

Adriana, L., Irineu de, B., Jr., Eduardo Queiroz, P., Tábata Rejane, B., Hugo Tsugunobu Yoshida, Y., 2014. Literature review of humanitarian logistics research: trends and challenges. Journal of Humanitarian Logistics and Supply Chain Management 4, 95-130.

Agarwal, R., Dhar, V., 2014. Editorial-Big Data, Data Science, and Analytics: The Opportunity and Challenge for IS Research. Information Systems Research 25, 443-448.

Akter, S., Wamba, S.F., 2016. Big data analytics in E-commerce: a systematic review and agenda for future research. Electronic Markets, 1-22. 
Akter, S., Wamba, S.F., Gunasekaran, A., Dubey, R., Childe, S.J., 2016. How to improve firm performance using big data analytics capability and business strategy alignment? International Journal of Production Economics 182, 113-131.

Altay, N., Green, W.G., 2006. OR/MS research in disaster operations management. European journal of operational research $175,475-493$.

Barney, J., 1991. Firm resources and sustained competitive advantage. Journal of management 17, 99120.

Barton, D., Court, D., 2012. Making advanced analytics work for you. Harvard business review 90, 78.

Beath, C., Becerra-Fernandez, I., Ross, J., Short, J., 2012. Finding Value in the Information Explosion. MIT Sloan Management Review 53, 18-20.

Bengtsson, L., Lu, X., Thorson, A., Garfield, R. and Von Schreeb, J., 2011. Improved response to disasters and outbreaks by tracking population movements with mobile phone network data: a postearthquake geospatial study in Haiti. PLoS Med, 8(8), p.e1001083.

Bish, D., Agca, E., Glick, R., 2014. Decision support for hospital evacuation and emergency response. Annals of Operations Research 221, 89-106.

Bouchard, L., Albertini, M., Batista, R. and de Montigny, J., 2015. Research on health inequalities: A bibliometric analysis (1966-2014). Social Science \& Medicine, 141, pp. 100-108.

Boyd, D. and Crawford, K., 2012. Critical questions for big data: Provocations for a cultural, technological, and scholarly phenomenon. Information, communication \& society, 15(5), pp. 662-679.

Chang, V., 2015. Towards a Big Data system disaster recovery in a Private Cloud. Ad Hoc Networks 35, 65-82.

Chung, K. and Park, R.C., 2016. P2P cloud network services for IoT based disaster situations information. Peer-to-Peer Networking and Applications, 9(3), pp. 566-577.

Craglia, M., Ostermann, F. and Spinsanti, L., 2012. Digital Earth from vision to practice: making sense of citizen-generated content. International Journal of Digital Earth, 5(5), pp. 398-416.

Crawford, K. and Finn, M., 2015. The limits of crisis data: analytical and ethical challenges of using social and mobile data to understand disasters. GeoJournal, 80(4), pp.491-502.

Crooks, A., Croitoru, A., Stefanidis, A. and Radzikowski, J., 2013. \# Earthquake: Twitter as a distributed sensor system. Transactions in GIS, 17(1), pp.124-147.

Davenport, T., Barth, P., Bean, R., 2012. How 'Big Data' is Different. MIT Sloan Management Review 54, 43-46.

Davenport, T.H., 2013a. Analytics 3.0. Harvard Business Review 91, 64-72.

Davenport, T.H., 2013b. Keep Up with Your Quants. Harvard Business Review 91, 120-123. 
De Gennaro, M., Paffumi, E. and Martini, G. 2016. Big Data for Supporting Low-Carbon Road Transport Policies in Europe: Applications, Challenges and Opportunities. Big Data Research, 6, pp. 11-25.

De Longueville, B., Annoni, A., Schade, S., Ostlaender, N. and Whitmore, C., 2010. Digital earth's nervous system for crisis events: real-time sensor web enablement of volunteered geographic information. International Journal of Digital Earth, 3(3), pp.242-259.

Drosio, S. and Stanek, S. 2016. The Big Data concept as a contributor of added value to crisis decision support systems. Journal of Decision Systems, 25, pp. 228-239.

Fosso Wamba, S., Akter, S., Edwards, A., Chopin, G., Gnanzou, D., 2015. How 'big data' can make big impact: Findings from a systematic review and a longitudinal case study. International Journal of Production Economics 165, 234-246.

Earle, P., Guy, M., Buckmaster, R., Ostrum, C., Horvath, S. and Vaughan, A., 2010. OMG earthquake! Can Twitter improve earthquake response?. Seismological Research Letters, 81(2), pp. 246-251.

Emmanouil, D. and Nikolaos, D., Big data analytics in prevention, preparedness, response and recovery in crisis and disaster management. In The 18th International Conference on Circuits, Systems, Communications and Computers (CSCC 2015), Recent Advances in Computer Engineering Series (Vol. 32, pp. 476-482).

Fahimnia, B., Sarkis, J. and Davarzani, H., 2015. Green supply chain management: A review and bibliometric analysis. International Journal of Production Economics, 162, pp. 101-114.

Galindo, G., Batta, R., 2013. Review of recent developments in OR/MS research in disaster operations management. European Journal of Operational Research 230, 201-211.

Gamal Aboelmaged, M., 2010. Six Sigma quality: a structured review and implications for future research. International Journal of Quality \& Reliability Management, 27(3), pp. 268-317.

Gao, H., Barbier, G. and Goolsby, R., 2011. Harnessing the crowdsourcing power of social media for disaster relief. IEEE Intelligent Systems, 26(3), pp.10-14.

Gelernter, J. and Mushegian, N., 2011. Geo-parsing Messages from Microtext. Transactions in GIS, 15(6), pp. 753-773.

Ghosh, S. and Gosavi, A., 2017. A semi-Markov model for post-earthquake emergency response in a smart city. Control Theory and Technology, 1(15), pp. 13-25.

Goswami, S., Chakraborty, S., Ghosh, S. Chakrabarti, A. and Chakraborty, B. 2016. A review on application of data mining techniques to combat natural disasters. Ain Shams Engineering Journal.

Green, W.G., III and McGinnis, S.R. 2002. Thoughts on the higher order taxonomy of disasters. Notes on the Science of Extreme Situations Paper \#7.

Grinberger, A.Y. and Felsenstein, D., 2016. Dynamic agent based simulation of welfare effects of urban disasters. Computers, Environment and Urban Systems, 59, pp. 129-141. 
Grolinger, K., Mezghani, E., Capretz, M.A. and Exposito, E., 2016. Knowledge as a Service Framework for Collaborative Data Management in Cloud Environments-Disaster Domain. In Managing Big Data in Cloud Computing Environments (pp. 183-209). IGI Global.

Hassini, E., Surti, C. and Searcy, C. 2012. A literature review and a case study of sustainable supply chains with a focus on metrics. International Journal of Production Economics 140, pp. 69-82.

Hazen, B.T., Boone, C.A., Ezell, J.D. and Jones-Farmer, L.A., 2014. Data quality for data science, predictive analytics, and big data in supply chain management: An introduction to the problem and suggestions for research and applications. International Journal of Production Economics, 154, pp.72-80.

Hristidis, V., Chen, S.C., Li, T., Luis, S. and Yi Deng, 2010. Survey of data management and analysis in disaster situations. The Journal of Systems and Software 83, pp. 1701-1714.

Huang, Q. and Cervone, G., 2016. Usage of Social Media and Cloud Computing During Natural Hazards. TC Vance, N. Merati, C. Yang, and M. Yuan, Cloud Computing in Ocean and Atmospheric Sciences, pp. 297-324.

Hughes, A.L. and Palen, L., 2009. Twitter adoption and use in mass convergence and emergency events. International Journal of Emergency Management, 6(3-4), pp.248-260.

Jahre, M., Persson, G., Kovács, G., Spens, K.M., 2007. Humanitarian logistics in disaster relief operations. International Journal of Physical Distribution \& Logistics Management 37, 99-114.

João Porto de Albuquerque, Benjamin Herfort, Alexander Brenning \& Alexander Zipf (2015) A geographic approach for combining social media and authoritative data towards identifying useful information for disaster management, International Journal of Geographical Information Science, 29:4, 667-689, DOI: 10.1080/13658816.2014.996567

Jean-Pierre, D., 2013. Oracle: Big Data for the Enterprise. USA: Oracle Corporation.

Ji-fan Ren, S., Fosso Wamba, S., Akter, S., Dubey, R., Childe, S.J., 2016. Modelling quality dynamics, business value and firm performance in a big data analytics environment. International Journal of Production Research, 1-16.

Kent, J.D. and Capello Jr, H.T., 2013. Spatial patterns and demographic indicators of effective social media content during the Horsethief Canyon fire of 2012. Cartography and Geographic Information Science, 40(2), pp.78-89.

Kim, G., Shin, B., Kwon, O., 2012. Investigating the Value of Sociomaterialism in Conceptualizing IT Capability of a Firm. Journal of Management Information Systems 29, 327-362.

Kiron, D., Prentice, P.K., Ferguson, R.B., 2014. The analytics mandate. MIT Sloan management review $55,1-25$.

Kitchin, R., 2014. The real-time city? Big data and smart urbanism. GeoJournal, 79(1), pp.1-14.

Landwehr, P.M. and Carley, K.M., 2014. Social media in disaster relief. In Data mining and knowledge discovery for big data (pp. 225-257). Springer Berlin Heidelberg. 
Liang, Y., Caverlee, J. and Mander, J., 2013, May. Text vs. images: on the viability of social media to assess earthquake damage. In Proceedings of the 22nd International Conference on World Wide Web (pp. 1003-1006). ACM.

Lukić, T., Gavrilov, M.B., Marković, S.B., Komac, B., Zorn, M., Mlađan, D., Đorđević, J., Milanović, M., Vasiljević, D.A., Vujičić, M.D. and Kuzmanović, B., 2013. Classification of natural disasters between the legislation and application: experience of the Republic of Serbia. Acta geographica Slovenica, 53(1), pp.149-164.

Mandel, B., Culotta, A., Boulahanis, J., Stark, D., Lewis, B. and Rodrigue, J., 2012, June. A demographic analysis of online sentiment during hurricane irene. In Proceedings of the Second Workshop on Language in Social Media (pp. 27-36). Association for Computational Linguistics.

Marr, B., 2015a. Big Data: A Game Changer In The Retail Sector, Forbes, p. 3.

Marr, B., 2015b. How Big Data Is Changing Healthcare, Forbes.

McGuire, B., 2012. How Climate Change Causes Earthquakes and Erupting Vol- canoes. The Guardian. http://www.motherjones.com/environment/2012/02/ climate-change-linked-to-volcano-eruptionsearthquakes (date of access 27.10.15.).

Mehrotra, S., Qiu, X., Cao, Z. and Tate, A. 2013. Technological challenges in emergency response. IEEE Intelligent Systems, 4, pp. 5-8.

Mendoza, M., Poblete, B. and Castillo, C., 2010, July. Twitter Under Crisis: Can we trust what we RT?. In Proceedings of the first workshop on social media analytics (pp. 71-79). ACM.

Menhart, M., 2015. How much can Australia’s economy withstand? Munich Re (Group).

Miller, G., 2013. 6 Ways To Use "Big Data” To Increase Operating Margins By 60\%.

Mukherjee, S., Chattopadhyay, M. and Chattopadhyay, S., 2015, February. A novel encounter based trust evaluation for AODV routing in MANET. In Applications and Innovations in Mobile Computing (AIMoC), 2015 (pp. 141-145). IEEE.

Nezih Altay, Walter G. Green. III. 2006. OR/MS research in disaster operations management. European Journal of Operational Research, 175, pp. 475-493.

Ng, R.T. and Han, J., 2002. CLARANS: A method for clustering objects for spatial data mining. IEEE transactions on knowledge and data engineering, 14(5), pp. 1003-1016.

Ngai, E.W.T., Chau, D.C.K., Poon, J.K.L., Chan, A.Y.M., Chan, B.C.M. and Wu, W.W.S., 2012. Implementing an RFID-based manufacturing process management system: Lessons learned and success factors. Journal of Engineering and Technology Management, 29(1), pp. 112-130.

Ngai, E.W., Poon, J.K.L., Suk, F.F.C. and Ng, C.C., 2009. Design of an RFID-based healthcare management system using an information system design theory. Information Systems Frontiers, 11(4), pp. 405-417. 
Ngai, E.W., Xiu, L. and Chau, D.C., 2009. Application of data mining techniques in customer relationship management: A literature review and classification. Expert systems with applications, 36(2), pp. 2592-2602.

Ngai, E.W.T., Moon, K.K., Riggins, F.J. and Candace, Y.Y., 2008. RFID research: An academic literature review (1995-2005) and future research directions. International Journal of Production Economics, 112(2), pp.510-520.

Ngai, E.W. and Gunasekaran, A., 2007. A review for mobile commerce research and applications. Decision Support Systems, 43(1), pp.3-15.

Ngai, E.W. and Wat, F.K.T., 2002. A literature review and classification of electronic commerce research. Information \& Management, 39(5), pp. 415-429.

O’Reilly, C.A., Tushman, M.L., 2008. Ambidexterity as a dynamic capability: Resolving the innovator's dilemma. Research in organizational behavior 28, 185-206.

Orlikowski, W.J., 2007. Sociomaterial practices: Exploring technology at work. Organization studies 28, $1435-1448$.

Özyer, T., Alhajj, R. and Barker, K., 2007. Intrusion detection by integrating boosting genetic fuzzy classifier and data mining criteria for rule pre-screening. Journal of Network and Computer Applications, 30(1), pp. 99-113.

Penurkar, M.R. and Deshpande, U.A., 2014, December. CONHIS: Contact history-based routing algorithm for a vehicular delay tolerant network. In India Conference (INDICON), 2014 Annual IEEE (pp. 1-6). IEEE.

Ponserre, S., Guha-Sapir. D, Vos F, Below R. Annual Disaster Statistical Review 2011: The Numbers and Trends. Brussels: CRED; 2012.

Poser, K., Dransch, D. (2010): Volunteered geographic information for disaster management with application to rapid flood damage estimation. - Geomatica, 64, 1, pp. 89-98

Pyakurel, U., Dhamala, T., 2017. Continuous Dynamic Contraflow Approach for Evacuation Planning. Annals of Operations Research 253, 573-598.

Qian, F., Chiew, K., He, Q., Huang, H. and Ma, L., 2013, April. Discovery of regional co-location patterns with k-nearest neighbor graph. In Pacific-Asia Conference on Knowledge Discovery and Data Mining (pp. 174-186). Springer Berlin Heidelberg.

Reddi, V.J., Lee, B.C., Chilimbi, T. and Vaid, K., 2011. Mobile processors for energy-efficient web search. ACM Transactions on Computer Systems (TOCS), 29(3), p. 9.

Robinson, B., Power, R. and Cameron, M., 2013, May. A sensitive twitter earthquake detector. In Proceedings of the 22nd International Conference on World Wide Web (pp. 999-1002). ACM.

Rovero, F. and Ahumada, J., 2017. The Tropical Ecology, Assessment and Monitoring (TEAM) Network: An early warning system for tropical rain forests. Science of The Total Environment, 574, pp. 914-923. Rowely, J. 2002. Using case studies in research, Management Research News, 25, 1, pp.16-27. 
Schläfke, M., Silvi, R., Möller, K., 2013. A framework for business analytics in performance management. International Journal of Productivity and Performance Management 62, 110-122.

Schnebele, E. and Waters, N., 2014. Road assessment after flood events using non-authoritative data. Natural Hazards and Earth System Sciences, 14(4), p.1007

Shelton, T., Poorthuis, A., Graham, M. and Zook, M., 2014. Mapping the data shadows of Hurricane Sandy: Uncovering the sociospatial dimensions of 'big data'. Geoforum, 52, pp. 167-179.

Smith, A.B. and Matthews, J.L., 2015. Quantifying uncertainty and variable sensitivity within the US billion-dollar weather and climate disaster cost estimates. Natural Hazards, 77(3), pp. 1829-1851.

Starbird, K. and Palen, L., 2010. Pass it on?: Retweeting in mass emergency (pp. 1-10). International Community on Information Systems for Crisis Response and Management.

Swiss Re Institute Sigma, 2017. Global insured losses from disaster events were USD 54 billion in 2016, up $42 \%$ from 2015. Swiss Re Institute Sigma.

Starr, M.K., Wassenhove, L.N.V., 2014. Introduction to the Special Issue on Humanitarian Operations and Crisis Management. Production and Operations Management 23, 925-937.

Tufekci, S. and Wallace, W.A., 1998. The emerging area of emergency management and engineering. IEEE Transactions on Engineering Management 45 (2), pp. 103-105.

Velev, D. and Zlateva, P. 2012 Use of Social Media in Natural Disaster Management, International proceedings of economics development and research, 39. Ed. Dong Lijuan. Singarpore: IACSIT Press. pp. 41-45.

Vieweg, S., 2010. Microblogged contributions to the emergency arena: Discovery, interpretation and implications. Computer Supported Collaborative Work, pp. 515-516.

Vieweg, S., Hughes, A.L., Starbird, K. and Palen, L., 2010, April. Microblogging during two natural hazards events: what twitter may contribute to situational awareness. In Proceedings of the SIGCHI conference on human factors in computing systems (pp. 1079-1088). ACM.

Wamba, S. F., Ngai, E. W. T., Riggins, F., \& Akter, S. (2017). Guest editorial. International Journal of Operations \& Production Management, 37(1), 2-9.

Wang, X., Wu, Y., Liang, L., Huang, Z., 2016. Service outsourcing and disaster response methods in a relief supply chain. Annals of Operations Research 240, 471-487.

Wang, Y., Chen, C., Wang, J. and Baldick, R., 2016. Research on resilience of power systems under natural disasters-A review. IEEE Transactions on Power Systems, 31(2), pp.1604-1613.

Waugh, W.L., Jr., 2000. Living with Hazards, dealing with Disasters: An Introduction to Emergency Management. M.E. Sharpe, Armonk, NY.

Wang, Y., Zhang, H., He, D., Guo, C., Zhu, W. and Yang, W. 2016. Function design and system architecture of disaster prevention and dispatch system in power system based on big data platform. Dianwang Jishu/Power System Technology, 40 (10), pp. 3213-3219. 
Yoo, J.S. and Shekhar, S., 2006. A joinless approach for mining spatial colocation patterns. IEEE Transactions on Knowledge and Data Engineering, 18(10), pp. 1323-1337.

Zhang, L., Liu, X., Li, Y., Liu, Y., Liu, Z., Lin, J., Shen, J., Tang, X., Zhang, Y. and Liang, W., 2012. Emergency medical rescue efforts after a major earthquake: lessons from the 2008 Wenchuan earthquake. The Lancet, 379(9818), pp. 853-861.

Zheng, L., Shen, C., Tang, L., Zeng, C., Li, T., Luis, S. and Chen, S.C., 2013. Data mining meets the needs of disaster information management. IEEE Transactions on Human-Machine Systems, 43(5), pp. 451-464.

Zook, M., Graham, M., Shelton, T. and Gorman, S., 2010. Volunteered geographic information and crowdsourcing disaster relief: a case study of the Haitian earthquake. World Medical \& Health Policy, 2(2), pp.7-33. 